\title{
COMMUNICATION ETHICS. AN OTHERS-CENTERED APPROACH TO CRISIS COMMUNICATION
}

\author{
Oana-Antonia ILIE \\ “Nicolae Bălcescu” Land Forces Academy, Sibiu, Romania \\ antonia_ilie@yahoo.com
}

\begin{abstract}
The present paper envisages an approach to the field of communication ethics, stressing on the importance of human relationship as a source of moral obligation and learning, and as a precondition of ethical communication. The second part of the paper advances the concept of other-centeredness as a solution to contemporary crisis management. In times of crisis, it often happens that organizations exert pressure on the media and the stakeholders for the sake of defending their own interests. In such moments organizations have the responsibility to engage in ethical communication with its public, by adopting a crisis response strategy in which honesty, human support and good of the people are prioritized, a communication strategy that places others first.
\end{abstract}

Keywords: communication ethics, ethical principles, other-centeredness, crisis communication

\section{Introduction}

We often hear that the world has become a dangerous place and that in order to survive we must become fierce ourselves. However, history has proven that the power of community can anytime, moreover with a minimum of effort, overcome chaos and reestablish, or reinvent the social order. We can only transcend the crisis that our society faces at the present time through the power of collaborative action, through intentional and mindful communication. During such times, when the collective voice is silenced, we find ourselves more than ever responsible to ask ourselves the fundamental ethical questions: How should we live? What is the best action to undertake? How should we communicate? Is there a good/just/normal way to communicate that would lead to beneficial outcomes?
In the last 100 years the Ethics of communication has produced questions and answers in regard to what can be considered right or wrong, moral or immoral in human communication and to what is the best strategy to create ethical worlds through the power of words. Scholars have identified the most important themes and shared norms in communication ethics: aspects related to power and responsibility, moral and emotional influence, the affirmation of such principles as truth, honesty, integrity, transparency, freedom of expression, respect, tolerance, the right to opinion, aspects regarding the communicational climate, the balance between criticism and appreciation, the compassion towards the other, and the interdictions to violate such principles: aspects related to abuse, manipulation, plagiarism, censorship, etc. 
Ethos, the Greek word for ethics is a term commonly associated with a person's "moral character." The second sense of ethos is what Isocrates referred to when he considered the nature of the orator's art: ethos is both a legitimating source for discourse and a praiseworthy effect.

"Who does not know that words carry greater conviction when spoken by men of good repute than when spoken by men who live under a cloud, and that the argument which is made by a man's life is more weight than that which is furnished by words?"[1]

For Aristotle, ethos is associated with the actual rhetorical competence displayed in the orator's discourse; ethos takes form as a result of the orator's abilities to argue and deliberate, thereby to inspire trust in an audience. While the art of rhetoric is referred to as persuasive communication, ethical judgments in rhetorical communication will be based on the intent of the source towards the audience. For Aristotle the pursuit of truth is the purpose of any theoretical attempt and the noblest of actions: logic is required to find the truth and rhetoric is necessary to communicate the truth.

In communication it is immoral to destroy someone's ground or standpoint (Bonhoeffer, 1949), the standard of communication ethics is the behavior that enhances the freedom of response of the listener (Keller, Brown, 1968); ethics is language bond (Gadamer, 1976); ethics should be applied to communicative action to assure that both the communicator and the message are ethical (Johannesen, 2002). With Bakhtin and Levinas' 20 ${ }^{\text {th }}$ century theories of answerability and responsibility, a new form of humanism can be envisaged, a "humanism of the other", oriented by the logic of otherness, responsive to the other. Mikhail Bakhtin's philosophy of human intersubjectivity assesses that only the human capacity for responsiveness/ answerability can indicate a capacity for "moral" responsibility. Levinas develops the concept of responsibility even further, as "the duty to give to the Other even the bread out of one's own mouth and the coat from one's shoulders"[2]; we are human beings in the sole measure that we are responsible for another (Levinas 1981).

Communication ethics is the call to learn from and about differing perspectives of the good assumed by different positions. Learning is the key of the encounter with difference, an act of learning from the narrative standpoints of the other:

"Learning is the central communication ethics principle in such an era, with engagement of difference, becoming a postmodern barometer of common sense" [3].

Ethical communication is more than an abstract theory; it is a way of life in which the communicators must be aware that through their daily communications they build the world. Whenever we communicate we make choices with ethical implications, whether they consist of transmitting or promoting human values, designing visions, making processes transparent, sharing ethical norms, developing core ethical practices or just giving support to the people in need.

\section{Ethical communication principles}

Ethical communication is not just transmitting and sharing our perspective on reality. It is an advocacy of realities (Brummet, 1976), a negotiation of competing views of the good or of competing narratives (Arnett, Arneson and Bell, 2006); any affirmation is pointless without the validation and confirmation that comes from the Other. Moreover, "acknowledgment of the Other" can be understood as the most primordial precondition of ethical communication.

"Acknowledgement of the Other is the one necessary discursive event that precedes the deployment of any conventional/normative commitments. Insofar as the Other is the source of ethical obligation, the acknowledgement of the Other has always already implicated human communication in the domain of the ethical" [4]. 
Habermas's (1990) discourse ethics depends on some pragmatic presuppositions of argumentation that promote the ideal community of communication and the capacity of communicators for moral dialogue. Habermas's validity conditions or assumptions of an effective communication refer to the rhetorical exigencies that communicators share, such as the expectations to pass the tests of comprehensibility, truth, sincerity, appropriateness. He asserts the existence of an ideal speech situation, that consists of the following elements:

\section{Participants must have equal opportunity to initiate and continue communicative acts;}

2. Participants must have equal opportunity to present arguments, explanations, interpretations and justifications;

3. Participants must have equal opportunities to express honestly personal intentions, feelings and attitudes;

4. Participants must have equal opportunity to present directive statements that forbid, permit, command, etc. [5].

Johnstone's (1981) ethical duties of any communicator include the pursuit of resoluteness, openness, gentleness and compassion. His basic imperative is to act on each instance as to encourage rather than suppress the capacity to persuade and to be persuaded. His responsible rhetoric is a self-perpetuary rhetoric, any techniques that block the persuasive responses being considered dehumanizing [6].

Johnstone's advices for an ethical content of rhetoric are that it "will articulate, clarify and affirm those human features that are most to be valued: our resourcefulness, our capacity for loving, our receptiveness and inclination toward beauty, our emotional resilience and range of sensitivities, our capacities for foresight and self-control, our capacities to wonder, our powers of passionate attachment, to name but a few. These are features that humans always embraced. These among the features that must be known and prized if we are to live a human life" [7].

Robert Scott (1967) asserts that the unique capacity of humans is their ability to generate / create knowledge, transmitting and creating truth in the interaction. Scott's four ethical amendments indicate that:

1. We should tolerate divergence of viewpoints and the right of others to self-express (otherwise we spoil our own potential of knowing);

2. We should consciously strive towards maximum participation in the process of development of contingent truth (other attitude should be considered ethical failure);

3. We should strive to achieve good consequences in our dialogue;

4. We should accept responsibility for undesirable consequences of our communication [8].

Verderber and Barryman (2007) elaborate five general principles that must make the norm of any conversation:

1. Truthfulness and honesty (the ethical communicator must always be honest, tell the truth and transmit viable, reliable information);

2. Integrity (the ethical speaker must be himself a model of integrity and not do other that he says);

3. Fairness (The ethical communicator will always treat people in an equal way, and will not break the ethical codes);

4. Respect (He will always show respect and appreciation for other people's values);

5. Responsibility (He will speak and act responsibly being aware of the consequences of his actions) [9].

As the semiotic school asserts, the importance of the human relationship is more often proven to prevail over the importance of the transmitted informational content. Thus, the first ethical thing to do is give the other a voice in the dialogue, instead of trying to silence it by treating him as an object or an unequal partner. Kant's imperative “Always act so as to treat humanity whether in your own person or in 
another as to an end and never as a means" could be considered a cornerstone ethical rule that must be applied to any communication.

\section{The others-centered crisis response}

According to Coombs (2015), an organizational crisis is usually understood as "the perception of an unpredictable event that threatens important expectancies of stakeholders and can seriously impact an [OC]'s performance and generate negative outcomes" [10]. A crisis should be at all times managed in an ethical manner, as ethics is regarded as the most important element in public relations practice.

In moments of crisis, it often happens that organizations will exert pressure on the media for the sake of defending their own interests. The act of communicating during such events consists of a complex and dynamic structure of communicative practices, unfolding before, during, and after the resented crisis. That is why in times of crisis, organizations are especially obliged to approach its public with honesty, transparency and respect, placing its good before its own interest.

Other-centeredness is a concept drawing upon a wide range of academic disciplines including biblical studies, feminist scholarship, philosophy, psychology, and theology. "Others-centeredness" is a behavioral disposition-a tendency to behave in such a way as to promote the good of others rather than one's own good. It basically tells us to listen, ask questions and empathize in order to truly understand. As St. Francis of Assisi said, Seek first to understand, then to be understood; once someone is heard and understood, they become more open to receive a different perspective, because they feel honored, respected, and valued. Other-centeredness philosophy can be used to improve ethical decision making in organizations, by promoting a culture that places the wellbeing of the others before organizational interests.

According to Austin \& Jin (2015), there are some major ethical tenets or guidelines for crisis reporting that must be followed such as respect, objectivity/neutrality, sensitivity, empathy/compassion, accuracy, timeliness, verification of facts/sources, honesty, transparency, and a strong focus on public interest [11].

The TARES Rule, according to Sherry Baker and David Marlinson (2001) draws attention to the 5 principles of professional persuasion, that apply in case of crisis:

1. Truthfulness of the message (honesty, trustworthyness, nondeceiptiveness);

2. Authenticity of the persuader (genuineness, integrity, ethical character,);

3. Respect for the interlocutor (regard for his rights, dignity and well being);

4. Equity (fairness, justice, nonexploitation of the vulnerability of others);

5. Social responsibility for the common good (concern for the public interest) [12].

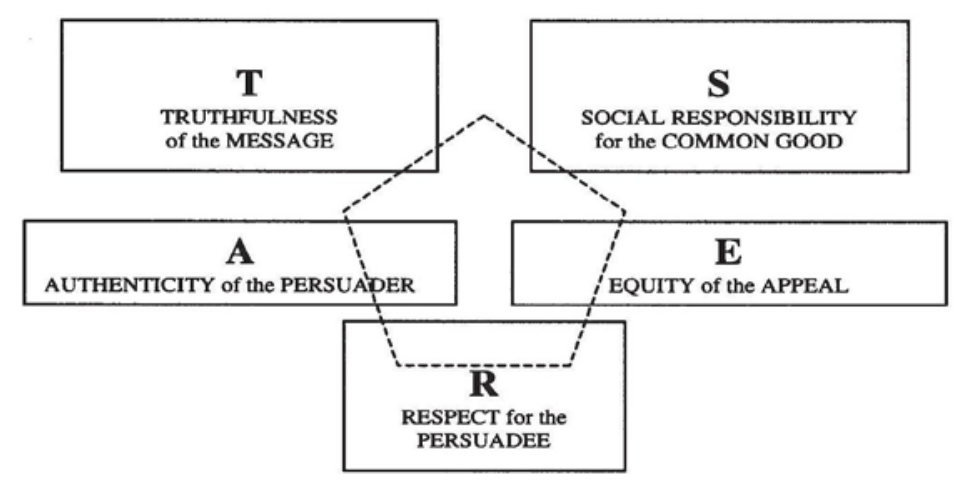

Figure 1 The TARES Test: Five principles for ethical persuasion. 
Concern and respect for the affected public should be an absolute priority. People are most sensitive in such cases to any attempt to manipulate or hide the truth behind the mediatized story. In addition, the managers and supervisors should communicate all the details of the crisis to employees. Employees and owners are the internal stakeholders that must be also managed with ethical integrity when a crisis occurs. It is important that they receive truthful, constant information updates as the crisis progresses. Face to face and online internal communication tools should be used as a way to clarify misunderstandings or rumors that may be circulating about the crisis. Most important, a somewhat optimistic approach must be encouraged, and a benevolent motivation towards "keeping the people's well-being in mind" as primary goal for ethical communication during a crisis.

James Lukaszewski in his 1997 article Establishing Individual and Corporate Communication Standards: The Principles and Protocols, indicates the next standards of crisis communication behavior:

1. Communication goals focused on meeting the expectations of constituents:

a. Openness and accessibility - availability and willingness to respond;

b. Truthfulness - unconditional honesty as the only policy;

c. Responsiveness - recognition that all concerns are legitimate and must be addressed accordingly;

c. No secrets - not hiding any relevant information.

2. Communication priorities for containing, controlling, and reducing the visibility and impact of emergent situations and the resulting damage to reputation:

a. Those directly affected (victims);

b. Employees;

c. Those indirectly affected such as neighbors, friends, families, customers, suppliers, and the government;

d. The news media and other channels of external communication.
3. Fundamental principles of crisis communication:

a. Communicate first with those most directly affected. The first obligation is to the health and safety of those people directly affected, to employees, and to the protection, resumption, recovery, and restoration of organizational reputation and processes;

b. Local communication is best. Local facility managers and operational personnel are generally part of the community and make credible and effective spokespersons for localized events;

c. One voice but not necessarily a single spokesperson. The information content should be unitary: accuracy, consistency, and promptness are keys to successful crisis communication;

d. Act quickly in communicating the crisis news. Present the events as they unfold in order to establish control and the impression that you are on top of the crisis.

e. Cooperate with the media. Respond promptly to press inquiries according to the priorities stated earlier;

f. Make fundamentally sound decisions based upon defendable criteria;

g. If the crisis involves questions of integrity, moral or ethical dilemmas, do the moral questioning quickly and take appropriate action promptly;

h. Use methodical problem- solving and decision-making processes [13].

Among the features of ethical communication during the crisis, empathy, respect, compassion, responsiveness, along with accuracy, transparency and accountability, prioritizing clarity over urgency are some of the main amendments. Releasing crisis information that is publicoriented, trust-worthy and consistent should be considered as the critical indicator of ethical communication.

\section{Conclusions}

Ethical communication in times of crisis seems to be the ongoing theme in today's communication research and practice. For 
many organizations, engaging in ethical communication during such times is the first important aspect to consider, as the abilities of organizations to communicate responsibly with honesty, providing solutions and human support are essential. Successful public relations hinges on the ethics of its practitioners, but also on the organization's communication strategy, that must place the good of the others first. This type of strategy requires flexible and people-oriented goals, based on thoughtful planning and practice. The messages need to be consistent and align with the organization's vision, mission and core values. Besides, practitioners need to be mindful and fully aware of the personal, situational and relational factors, especially when putting people first implies expressing sympathy or compassion for the victims, their families and other affected publics. Striving to achieve the wellbeing of the organization without or indifferent to meeting the interests of the publics involved is a sign of an unethical culture, regardless of the stated values and the communication strategy. In conclusion, an other-centered crisis approach is adopting the authentic deontological position meaning that the intention behind the message is just as important as the message itself.

\section{References List}

[1] Isocrates Antidosis (G. Norlin, Trans.). Cambridge, MA: Harvard University Pres, 1982, p. 278.

[2] Levinas, E. Otherwise than being or beyond essence, Translated by A. Lingis. The Hague: Nijhoff, 1981, p. 55.

[3] Pat Arneson, Exploring Communication Ethics: Interviews with Influential Scholars in the Field, Peter Lang Publishing, New York, 2007, p. 54.

[4] Murray, J. W. Toward a post-Habermasian discourse ethics: The acknowledgment of the other. New Jersey Journal of Communication, 9(1), 2001, p.1-19.

[5] Habermas, J. Discourse ethics: Notes on a program of philosophical justification. In Moral consciousness and communicative action, Cambridge, MA: MIT Press 1990, p. 177-178.

[6]. Richard L. Johannesen, Kathleen S. Valde, Karen E. Whedbee, Ethics in Human Communication: Sixth Edition, 2007, p. 40.

[7] Johnstone, C.L., Ethics, wisdom and the mission of contemporary rhetoric. The realization of human being, Central States Speech Journal, 32, 1981, p.177-188.

[8] Richard L. Johannesen, Kathleen S. Valde, Karen E. Whedbee, op.cit, p. 43.

[9] Verderber, Kathleen S., Verderber, Rudolf F., and Berryman-Fink, Cynthia. Inter-Act: interpersonal communication concepts, skills, and contents. 11th ed. Oxford University Press, 2007.

[10] Timothy W.Coombs, Ongoing crisis Communication, Planning, Managing and Responding, Second Edition, 2015, p. 3.

[11] Austin \& Jin, Approaching Ethical Crisis Communication Public Relations Journal, Vol. 9, No. 1 (Spring 2015) 7 term.

[12] Sherry Baker, David L. Martinson, The TARES Test: Five Principles for Ethical Persuasion, Journal of Mass Media Ethics, 16(2\&3), Lawrence Erlbaum Associates, Inc., 2001, p.148-175.

[13] Lukaszewski, James E. Establishing Individual and Corporate Crisis Communication Standards: The Principles and Protocols”, Public Relations Quarterly. Vol. 42, No. 3. 1997, p. 7-14. 